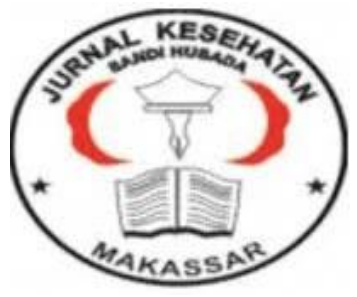

\author{
Jurnal Ilmiah Kesehatan Sandi Husada \\ hhttps://akper-sandikarsa.e-journal.id/JIKSH \\ Volume 9, Nomor 2, Desember 2020, pp 889-896 \\ p-ISSN: 2354-6093 dan e-ISSN: 2654-4563 \\ DOI: $10.35816 /$ jiskh.v10i2.367
}

\title{
Analisis Seri Kasus Pseudoaneurysm Setelah Trauma Ginjal Tumpul
}

Pseudoaneurysm in Renal Blunt Trauma Case Series Analysis

\author{
Arifah Zanuar Kumalasari ${ }^{1}{ }^{*}$, Agus Sudaryanto ${ }^{2}$ \\ 12 Program Studi Ners Fakultas Ilmu Kesehatan Universitas Muhammadiyah Surakarta \\ Artikel info
}

Artikel history:

Received; Juni 2020

Revised: Juli 2020

Accepted;Juli 2020
Abstrak. Pendahuluan: Trauma ginjal terjadi sekitar 1-5\% dari kejadian seluruh trauma dan sekitar 10\% pasien mengalami tarauma abdomen. Pseudoaneurysm merupakan komplikasi vaskular yang jarang terjadi setelah trauma tumpul. Tujuan dari penulisan ini ingin menganalisis kasuskasus pseudoaneurysm setelah trauma ginjal tumpul. Metode: Desain yang digunakan dalam study literature ini menggunakan desain literature review. Analisis yang digunakan penulis yaitu analisis narrative review. Pencarian artikel menggunakan PubMed dan Google Scholar sesuai tema yang dipilih kemudian dilakukan review. Hasil: Dari 5 artikel yang mengalami pseudoaneurysm setelah trauma tumpul ginjal diderita terbanyak pada laki-laki. Empat kasus disebabkan karena jatuh. Tanda dan gejala dari lima kasus yaitu penurunan kadar hemoglobin darah dan gross hematuria. Empat kasus mengalami trauma ginjal tumpul dibagian kanan dan hasil CT Scan menunjukkan 3 kasus pada derajat III. Diskusi: Pada kalangan dewasa yang sering ditemukan yaitu laki-laki saat usia produktif. Umur seseorang menjadi faktor resiko terjadinya pseudoaneurysm setelah trauma tumpul ginjal. Pemeriksaan hematokrit disertai dengan pemeriksaan hemoglobin darah berperan untuk mengetahui tanda perdarahan aktif yang dicurigai adanya penurunan kadar hemoglobin. Kesimpulan: Analisis dari ke lima artikel didapatkan adanya tanda gross hematuria dan penurunan kadar hemoglobin darah serta tindakan medis yang sering digunakan yaitu embolisasi

Abstract. Introduction: Renal trauma occurs about 1-5\% of all trauma events and about 10\% of patients experience abdominal tarauma. Pseudoaneurysm is a vascular complication that rarely occurs after blunt trauma. The purpose of this paper is to analyze pseudoaneurysm cases after blunt kidney trauma. Method: The design used in the study literature uses a literature review design. The analysis 
used by the writer is a narrative review analysis. Search for articles using PubMed and Google Scholar according to the chosen theme then do a review. Results: Of the 5 articles that experienced pseudoaneurysm after blunt kidney injury suffered the most in men. Four cases were caused due to falls. Signs and symptoms of five cases are decreased blood hemoglobin levels and gross hematuria. Four cases had blunt kidney trauma on the right side and the CT scan showed 3 cases in grade III. Discussion: Among adults who are often found are men at productive age. A person's age is a risk factor for pseudoaneurysm after blunt kidney injury. Hematocrit examination accompanied by examination of blood hemoglobin plays a role in identifying signs of active bleeding that are suspected of having decreased hemoglobin levels. Conclusion: Analysis of the five articles found a sign of gross hematuria and a decrease in blood hemoglobin levels and a medical treatment that is often used is embolization.

Keywords:

Pseudoaneurysm;

Kidney;

Blunt Trauma;

Embolization;
Coresponden author:

Email: arifah.kumalasari@gmail.com

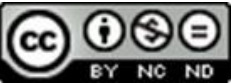

artikel dengan akses terbuka dibawah lisensi BCC BY NC ND-4.0

\section{Pendahuluan}

Trauma merupakan penyebab utama kematian dan kecacatan di seluruh dunia. Trauma tumpul abdomen terjadi adanya tekanan atau pukulan langsung ataupun deselerasi pada dinding abdomen tetapi tidak menimbulkan luka terbuka. Di Amerika Serikat, kecelakaan lalu lintas merupakan penyebab utama terjadinya trauma tumpul abdomen dan sekitar $50-75 \%$ mengalami trauma yang cukup serius. Organ yang sering mengalami trauma abdomen antara lain limpa (40-45\%, hati (35-45\%) dan ginjal karena organ-organ tersebut termasuk organ yang solid di abdomen (Khoschnau \& Al-hassani, 2019). Pada tahun 2013 pravalensi cedera di Indonesia sebanyak 8,2\%, dengan urutan penyebab cedera terbanyak adalah jatuh 40,9\%, kecelakaan sepeda motor $(40,6 \%)$, cedera karena benda tajam/tumpul 7,3\%, transportasi darat lainnya 7,1\% dan kejatuhan sebanyak 2,5\% (Badan Penelitian dan Pengembangan Kesehatan RI, 2013).

Trauma ginjal terjadi sekitar 1-5\% dari kejadian seluruh trauma dan sekitar 10\% pasien mengalami tarauma abdomen (Indradiputra \& Hartono, 2016). Organ ginjal merupakan organ saluran kemih yag paling sering terkena cedera pada kasus trauma. Trauma ginjal terjadi pada $0,3-3,25 \%$ pasien trauma dan $71-95 \%$ trauma ginjal disebabkan karena trauma tumpul. Trauma ginjal tumpul paling banyak diakibatkan oleh kecelakaan lalu lintas, jatuh dan cedera akibat olahraga. Kecelakaan lalu lintas merupakan penyebab tersering dari trauma ginjal tumpul sedangkan pada anak-anak, kecelakaan lalu lintas dan jatuh merupakan penyebab tersering dari trauma ginjal tumpul (Dangle, et al., 2016). Faktor risiko trauma ginjal tumpul pada orang dewasa yaitu riwayat kelainan ginjal sebelumnya, usia, jenis kelamin dan jenis aktivitas. Laki-laki usia produktif banyak ditemukan mengalami trauma ginjal tumpul dari kalangan penderita dewasa (Erlich \& Kitrey, 2018). 
Trauma ginjal dapat menyebabkan beberapa komplikasi baik yang segera (misalnya: perdarahan, infeksi, abses perinefrik, sepsis, fistula, hipertensi, urinoma dan ekstravasasi urin) ataupun komplikasi tertunda (misalnya: hidronefrosis, batu saluran kemih, pielonefritis kronis, fistula arterivena dan pseudoaneurysm (Indradiputra \& Hartono, 2016). Pseudoaneurysm yang pecah merupakan kejadian yang menyebabkan perdarahan sekunder atau hematuria persisten setelah trauma tumpul ginjal. Ginjal ditutupi oleh lemak dan fasia gerota di retroperitoneum yang biasanya mengandung perdarahan setelah cedera ginjal dan perdarahan terbatas ini dapat menyebabkan pseudoaneurysm setelah fibrinolisis dan rekanalisasi abnormal antara ruang intravaskular dan jaringan perinefrik atau ekstravaskular (Wesselles, 2013). Pseudoaneurysm adalah komplikasi vaskular yang jarang terjadi, secara etiologis terkait dengan nefrektomi parsial, biopsi ginjal, trauma penetrasi, prosedur perkutan dan lebih jarang trauma tumpul (Roman, Luiz Inacio et al, 2017).

Dengan dukungan teori, pengamatan dan study case tentang pseudoaneurysm karena trauma ginjal tumpul maka penulis tertarik untuk menganalisis kasus pseudoaneurysm karena trauma tumpul ginjal. Tujuan dari study literature ini adalah ingin menganalisis kasus-kasus pseudoaneurysm karena trauma ginjal tumpul.

\section{Metode}

Desain yang digunakan dalam study literature ini menggunakan desain literature review. Analisis yang digunakan penulis yaitu analisis narrative review. Subyek review ini adalah semua artikel yang membahas tentang kasus pseudoaneurysm karena trauma tumpul ginjal. Literature review dari laporan kasus disusun melalui penelusuran artikel penelitian yang sudah terpublikasi. Populasinya adalah semua artikel yang ada di internet dan sampelnya ialah artikel yang ada diinternet tentang pseudoaneurysm karena trauma ginjal tumpul. Pencarian dilakukan menggunakan PubMed dan Google Scholar dengan kata kunci tiap variabel yang telah dipilih. Artikel yang ditemukan dibaca dan dicermati untuk melihat apakah artikel memenuhi kriteria inklusi penulis untuk dijadikan sebagai literatur dalam penulisan literature review. Pencarian berbatas dimulai pada tahun 2016 sampai tahun 2020 yang diakses fulltext dalam format pdf. Artikel penelitian laporan kasus yang terpublikasi mengenai pseudoaneurysm karena trauma ginjal tumpul akan dimasukkan dalam literature review. Langkah pencarian artikel melalui data based dengan kata kunci: Pseudoaneurysm, kidney, blunt trauma. Pencarian artikel dilakukan melalui PubMed dan Google Scholar dengan kata kunci tersebut dan menghasilkan beberapa artikel. Setelah dilakukan seleksi berdasarkan kriteria didapatkan 5 artikel dengan kriteria inklusi dan eksklusi, ke lima artikel tersebut kemudian dianalisis. Artikel eligible jika memenuhi kriteria inklusi yaitu kesesuaian topik, metode yang digunakan sedangkan tidak eligible jika tidak publikasi lima tahun terakhir. Di bawah ini merupakan 5 daftar artikel yang di ekstraksi dalam bentuk tabel:

Penelusuran full text PDF

2016-2020

Eligible dengan kriteria inklusi

Eligible untuk dianalisis

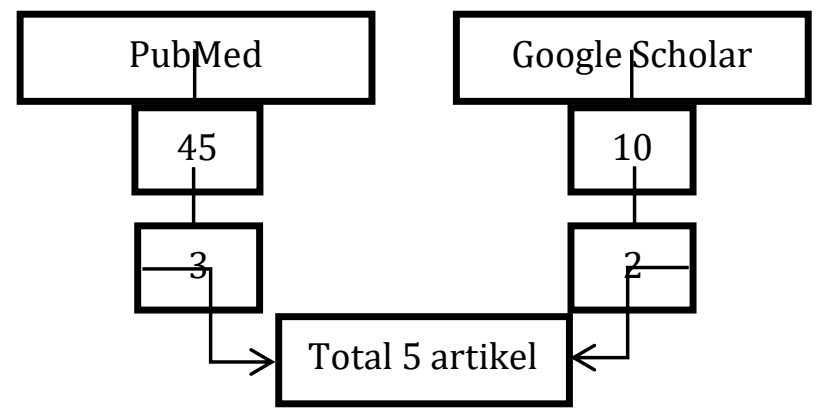

Gambar 1. Flow Chart Artikel 


\section{Hasil Dan Pembahasan}

Tabel 1. Data Demografi Pasien Pseudoaneurysm setelah Trauma Tumpul Ginjal

\begin{tabular}{|c|c|c|c|c|c|c|}
\hline Studi/Outhor & $\begin{array}{c}\text { Tempat } \\
\text { Penelitian }\end{array}$ & Sampel & Umur & $\begin{array}{c}\text { Jenis } \\
\text { Kelamin }\end{array}$ & Pendidikan & Asal Negara \\
\hline $\begin{array}{l}\text { Renal Pseudoaneurysm and } \\
\text { Pulmonary Embolism: A } \\
\text { Unique Manifestation of } \\
\text { Complications Following } \\
\text { Blunt Renal Trauma/ Gstrein, } \\
\text { L., Antwerpen, I., Martin, H., } \\
\text { Kwiatkowski, M., Wyler, S., \& } \\
\text { Walter, M. (2019) }\end{array}$ & Kanada & 1 & $\begin{array}{c}71 \\
\text { tahun }\end{array}$ & Laki-laki & - & Kanada \\
\hline $\begin{array}{l}\text { Renal Pseudoaneurysm After } \\
\text { Blunt Trauma In A 10-Years- } \\
\text { Old Girl: A Case Report/ } \\
\text { Sforza, S., Persano, G., Cini, C., } \\
\text { Sforzi, I., Grosso, A. A., } \\
\text { Bronzini, F., ... Masieri, L. } \\
(2020)\end{array}$ & Italia & 1 & $\begin{array}{c}10 \\
\text { tahun }\end{array}$ & $\begin{array}{c}\text { Peremp } \\
\text { uan }\end{array}$ & $\begin{array}{c}\text { Scuola } \\
\text { Primer } \\
\text { (SD) }\end{array}$ & Italia \\
\hline $\begin{array}{l}\text { Intraparenchymal Renal } \\
\text { Artery Pseudoaneurysm and } \\
\text { Arteriovenous Fistula on A } \\
\text { Solitary Kidney Occurring } 38 \\
\text { Years after Blunt Trauma/ } \\
\text { Benamran, D., Clippele, B. De, } \\
\text { Hammer, F., \& Tombal, B. } \\
(2017)\end{array}$ & Swiss & 1 & $\begin{array}{c}53 \\
\text { tahun }\end{array}$ & $\begin{array}{l}\text { Laki- } \\
\text { laki }\end{array}$ & - & Swiss \\
\hline $\begin{array}{l}\text { Endovascular } \\
\text { Angioembolization of } \\
\text { Intrarenal Pseudoaneurysm } \\
\text { in Ectopic Kidney After Blunt } \\
\text { Abdominal Trauma/ Agarwal, } \\
\text { V., \& Gorsi, U. (2017) }\end{array}$ & $\begin{array}{c}\text { Chandig } \\
\text { arh, } \\
\text { India }\end{array}$ & 1 & $\begin{array}{c}21 \\
\text { tahun }\end{array}$ & $\begin{array}{l}\text { Laki- } \\
\text { laki }\end{array}$ & - & India \\
\hline \multirow{3}{*}{$\begin{array}{l}\text { Endovascular Treatment of } \\
\text { Splanchnic Pseudoaneurysms } \\
\text { Following Blunt Solid Organ } \\
\text { Injuries in Children/ Oliveira, } \\
\text { J. A., Costa, N. V., Bilhim, T., } \\
\text { Gomes, F. V., \& Coimbra, E. } \\
(2018)\end{array}$} & $\begin{array}{l}\text { Porto, } \\
\text { Portugal }\end{array}$ & 3 & $\begin{array}{c}6 \\
\text { tahun }\end{array}$ & $\begin{array}{l}\text { Laki- } \\
\text { laki }\end{array}$ & $\begin{array}{c}\text { Pendidika } \\
\text { n Dasar }\end{array}$ & Portugal \\
\hline & & & $\begin{array}{c}12 \\
\text { tahun }\end{array}$ & $\begin{array}{c}\text { Peremp } \\
\text { uan }\end{array}$ & - & \\
\hline & & & $\begin{array}{c}17 \\
\text { tahun }\end{array}$ & $\begin{array}{l}\text { Laki- } \\
\text { laki }\end{array}$ & - & \\
\hline Rata-rata um & & & & & 1 tahun & \\
\hline
\end{tabular}

(Gstrein, L. et al., 2019; Sforza, S. et al., 2020; Benamran, D., Clippele, B. De, Hammer, F., \& Tombal, B., 2017; Agarwal, V., \& Gorsi, U., 2017; Oliveira, J. A. et al., 2018). 
Tabel 2. Data Klinis Pasien Pseudoaneurysm setelah Trauma Tumpul Ginjal

\begin{tabular}{ll}
\hline \multicolumn{1}{c}{ Data Klinis } & Jumlah \\
\hline Jenis kelamin & \\
\hline$-\quad$ Laki-laki & 5 pasien $(71,4 \%)$ \\
\hline$-\quad$ Perempuan & 2 pasien $(28,6 \%)$ \\
\hline Keaadaan kejadian & 1 pasien $(14,3 \%)$ \\
\hline$-\quad$ Kecelakaan lalu lintas & 2 pasien $(28,6 \%)$ \\
\hline$-\quad$ Cedera olahraga & 4 pasien $(57,1 \%)$ \\
\hline$-\quad$ Jatuh & 5 pasien $(71,4 \%)$ \\
\hline Gross hematuria & 5 pasien $(71,4 \%)$ \\
\hline Hemoglobin rendah & \\
\hline Sisi trauma & 3 pasien $(42,9 \%)$ \\
\hline$-\quad$ Kiri & 4 pasien $(57,1 \%)$ \\
\hline$-\quad$ Kanan & \\
\hline Grade trauma tumpul ginjal & 1 pasien $(14,3 \%)$ \\
\hline$-\quad$ I & - \\
\hline$-\quad$ II & 3 pasien $(42,9 \%)$ \\
\hline$-\quad$ III & 2 pasien $(28,6 \%)$ \\
\hline$-\quad$ IV & 5 pasien $(71,4 \%)$ \\
\hline Penggunaan embolisasi ginjal & (n)
\end{tabular}

(Gstrein, L. et al., 2019; Sforza, S. et al., 2020; Benamran, D., Clippele, B. De, Hammer, F., \& Tombal, B., 2017; Agarwal, V., \& Gorsi, U., 2017; Oliveira, J. A. et al., 2018)

Penetapan kriteria yang tepat pada metode sangat mempengaruhi jumlah artikel yang dihasilkan. Penentuan artikel yang diambil untuk literature review ini menggunakan metode artikel laporan kasus dengan rentang tahun 2016-2020. Hasil secara keseluruhan dari artikel laporan kasus yang digunakan dalam literature review ini bahwa pseudoaneurysm jarang terjadi setelah trauma ginjal tumpul baik pada orang dewasa maupun pada anak-anak. Pada ke lima artikel yang didapatkan umur pasien antara laian 71 tahun, 10 tahun, 53 tahun, 21 tahun, 6 tahun, 12 tahun, 17 tahun, sehingga rata-rata umurnya 27 tahun. Umur yang paling muda menunjukkan umur 6 tahun dan umur maksimal pada ke tujuh pasien dari lima artikel yaitu 71 tahun. Pseudoaneurysm karena trauma ginjal tumpul tidak hanya terjadi pada orang dewasa tapi terjadi pada anak-anak juga. Pada hasil analisis dari kelima artikel tersebut, pasien yang mengalami pseudoaneurysm karena trauma tumpul ginjal paling banyak adalah berjenis kelamin lakilaki sebanyak 5 pasien (71,4\%). Menurut Erlich \& Kitrey (2018), pada kalangan dewasa yang sering ditemukan yaitu laki-laki saat usia produktif. Umur seseorang menjadi faktor resiko terjadinya pseudoaneurysm karena trauma tumpul ginjal.

Menurut Erlich \& Kitrey (2018), trauma tumpul ginjal disebabkan karena kecelakaan lalu lintas sedangkan pada anak-anak yang sering terjadi disebabkan jatuh dan kecelakaan lalu lintas. Berdasarkan analisis dari ke lima artikel ini didapatkan bahwa pseudoaneurysm karena trauma tumpul ginjal disebabkan pasien jatuh sebanyak 4 pasien $(57,1 \%)$. Ke tujuh pasien dari lima artikel, 5 pasien $(71,4 \%)$ ditandai adanya gross hematuria dan mengalami penurunan kadar hemoglobin. Menurut Froehner (2017) pseudoaneurysm dapat menyebabkan hematuria secara berulang setelah trauma ginjal tumpul. Hematuria baik mikroskopik atau gross/makroskopik sering dijumpai pada kondisi trauma ginjal, akan tetapi tidak spesifik untuk membedakan trauma minor maupun mayor. Pemeriksaan hematokrit disertai dengan pemeriksaan hemoglobin darah berperan untuk mengetahui tanda perdarahan aktif yang dicurigai adanya penurunan kadar hemoglobin (Indradiputra dan Hartono, 2016). 
Pada hasil analisis, grade trauma tumpul ginjal paling banyak pada grade III yaitu 3 pasien $(42,9 \%)$ dan kebanyakan mengalami trauma tumpul ginjal di bagian sebelah kanan yaitu 4 pasien $(57,1 \%)$. Penentuan derajat trauma ginjal ditentukan berdasarkan hasi CT Scan mengikuti tatalaksan pasien trauma berdasarkan klasifikasi American Association for the Surgery of Trauma (AAST) (Indradiputra dan Hartono, 2016). Pada penderita pseudoaneurysm karena trauma ginjal tumpul perlu dilakukan tindakan nonoperatif (konservatif) atau operatif. Tindakan ini tergantung pada jenis trauma yang dialami dan status hemodinamik pasien. Penggunaan embolisasi ginjal pada ke lima artikel terdapat 5 pasien $(71,4 \%)$. Berdasarkan hasil penelitian dari Guyot, et al (2017), mengatakan bahwa tindakan embolisasi memungkinkan pelestarian ginjal yang baik dengan tingkat keberhasilan 84,6\% dan tidak ada komplikasi yang terjadi.

Stabilitas hemodinamik dan strategi konservatif yang terdiri dari tirah baring, pemberian cairan intravena, pemantauan kilinis dan pengecekan tes laboratorium diperlukan dalam tatalaksana pasien pseudoaneurysm setelah trauma tumpul ginjal (Sforza, Simone, et al, 2020). Penatalaksanaan pada pasien trauma tumpul pada saat di IGD yaitu berfokus yaitu memerlukan penilaian dan sistem perawatan yang cepat dan terorganisir. Manajemen awal pasien dilakukan survei primer, yang bertujuan untuk mengidentifikasi dan mengobati cedera yang membahayakan nyawa pasien dan survei sekunder, yang berupaya untuk mendeteksi semua cedera serta memulai perawatan definitif (Amend, B., Stenzl, A., \& Bedke, J., 2016).

Bagian pertama dari survei primer yaitu menilai jalan napas, memeriksa kemungkinan cedera pada tulang belakang. Jika tidak ditemukan lanjutkan tindakan selanjutnya yaitu membuka jalan nafas pasien dengan chin lift maneuver. Apabila ada makanan, darah, muntah, bebaskan jalan napas dengan cepat untuk mencegah aspirasi. Jika pasien tidak dapat mempertahankan jalan napas paten, perlu intubasi endotrakeal. Penilaian ke dua yaitu menilai pernapasan, meliputi kecepatan dan kedalaman pernapasan, ekspansi dada, penggunaan otot tambahan dan napas auskultasi bunyi bilateral. Meraba adanya krepitus di leher dan dada yang dapat mengindikasi adanya pneumotoraks. Penilaian ke tiga yaitu sirkulasi, nilai kualitas dan terabanya nadi perifer harus diperhatikan, warna kulit dan tingkat kesadaran pasien (LOC). Kulit pucat dan dingin, lembab mengindikasikan syok. Memantau tekanan darah dan tanda-tanda vital setiap 5 hingga 15 menit sampai kondisi pasien membaik. Penilaian disabilitas, meliputi mengevaluasi LOC dengan menilai GCS pasien, respon pupil dan fungsi sensorimotorik. Selanjutnya survei sekunder, dimulai dari kepala dan nilai secara metodis. Memeriksa kontusio, abrasi, laserasi, deformitas, perubahan warna, edema, benda asing dan kelainan lainnya. Mengkaji semua area tubuh untuk menemukan area nyeri, krepitus, deformitas, kehilangan fungsi dan lokasi serta kualitas denyut nadi (Amend, B., Stenzl, A., \& Bedke, J., 2016). 


\section{Simpulan Dan Saran}

Pseudoaneurysm merupakan salah satu komplikasi tertunda yang jarang terjadi setelah trauma tumpul pada ginjal dan biasanya dikaitkan dengan perkembangan nontraumatis. Berdasarkan analisis dari ke lima artikel didapatkan adanya tanda gross hematuria dan penurunan kadar hemoglobin darah serta tindakan medis yang sering digunakan yaitu embolisasi. Pseudoaneurysm setelah trauma ginjal tumpul dapat dijumpai walaupun jarang terjadi. Setiap kasus memiliki tanda dan gejala berbeda-beda, biasanya ditemukan adanya hematuria dan penurunan hemoglobin

\section{Daftar Rujukan}

Khoschnau, S., \& Al-hassani, A. (2019). Urologia Traumatic Kidney Injury : An Observational Descriptive Study. Urologia Internationalis, 104(1-2), 147-154. https://doi.org/10.1159/000504895

Badan Penelitian dan Pengembangan Kesehatan. (2013). Riset Kesehatan Dasar 2013. Pedoman Pengisian Kuesioner. Jakarta, p. 31-95.

Indradiputra, I. M., \& Hartono, T. (2016). Tatalaksana Konservatif Pasien Dewasa dengan Trauma Tumpul Ginjal Derajat IV Terisolasi. Cermin Dunia Kedokteran, 43(2), 123126.

Dangle, A. P., Fuller, T. W., Gaines, B., Cannon, G. M., Schneck, F. X., Stephany, H. A., et al. (2016). Evolving Mechanisms of Injury and Management of Pediatric Blunt Renal Trauma - 20 Years of Experience. Urology, 90, 159-163. https://doi.org/10.1016/j.urology.2016.01.017

Erlich T, Kitrey ND. (2018). Renal trauma: the current best practice. Therapeutic advances in urology. 10 (10): 295-303. https://doi.org/10.1177/1756287218785828

Wessells, Hunter. (2013). Urological Emergencies: A Practical Approach. New York: Human Press.

Roman, Luiz Inacio, et al. (2017). Renal Artery Pseudoaneurysm. Brazilian Journal of Nephrology, 39(4), 458-461. https://doi.org/10.5935/0101-2800.20170080

Gstrein, L., Antwerpen, I., Martin, H., Kwiatkowski, M., Wyler, S., \& Walter, M. (2019). Urology Case Reports Renal pseudoaneuryms and pulmonary embolism : A unique manifestation of complications following blunt renal trauma. Urology Case Reports, 24, 100835. https://doi.org/10.1016/j.eucr.2019.01.016

Sforza, S., Persano, G., Cini, C., Sforzi, I., Grosso, A. A., Bronzini, F., ... Masieri, L. (2020). Renal Pseudoaneurysm After Blunt Trauma In A 10-Years-Old Girl: A Case Report. Urologi Journal, 0391560319896155, 1-3.

https://doi.org/10.1177/0391560319896155

Benamran, D., Clippele, B. De, Hammer, F., \& Tombal, B. (2017). Intraparenchymal Renal Artery Pseudoaneurysm and Arteriovenous Fistula on A Solitary Kidney Occurring 38 Years after Blunt Trauma. Case reports in urology, 2017, 3017501. https://doi.org/10.1155/2017/3017501

Oliveira, J. A., Costa, N. V., Bilhim, T., Gomes, F. V., \& Coimbra, E. (2018). Endovascular Treatment of Splanchnic Pseudoaneurysms Following Blunt Solid Organ Injuries in Children. Acta Radiologica Portuguesa, 30(1), 15-22. https://doi.org/10.25748/arp.13548

Agarwal, V., \& Gorsi, U. (2017). Endovascular Angioembolization of Intrarenal Pseudoaneurysm in Ectopic Kidney after Blunt Abdominal Trauma. Indian Journal 
of Vascular and Endovascular Surgery, 4(4), 201-203.

https://doi.org/10.4103/ijves_25_17

Froehner, M., Schaab, F., Hofmockel, T., Hoffmann, R., Fahlenkamp, D., \& Wirth, M. P. (2017). Delayed Radiographic Manifestation of Renal Pseudoaneurysm After Blunt Trauma. Urology, 103, e9-e10.

https://doi.org/10.1016/j.urology.2017.02.013

Guyot, R., Arnoux, V., Descotes, J., Terrier, N., Boillot, B., Thuillier, C., ... Fiard, G. (2017). Management of Intraparenchymal Pseudoaneurysm after Blunt Renal Trauma: Results from a Series of 325 Patients. Progresen Urologie: Journal de L'association Francaise D'urologie et de la Sociate Francaise D'urologie, 27(3), 190-199.

https://doi.org/10.1016/j.purol.2016.12.012

Amend, B., Stenzl, A., \& Bedke, J. (2016). Contemporary Management of Acute Kidney Trauma. Journal of Acute Disease, 5(1), 29-36.

https://dx.doi.org/10.1016/j.joad.2015.08.003 